DOI: https://doi.org/10.47405/mjssh.v6i1.634

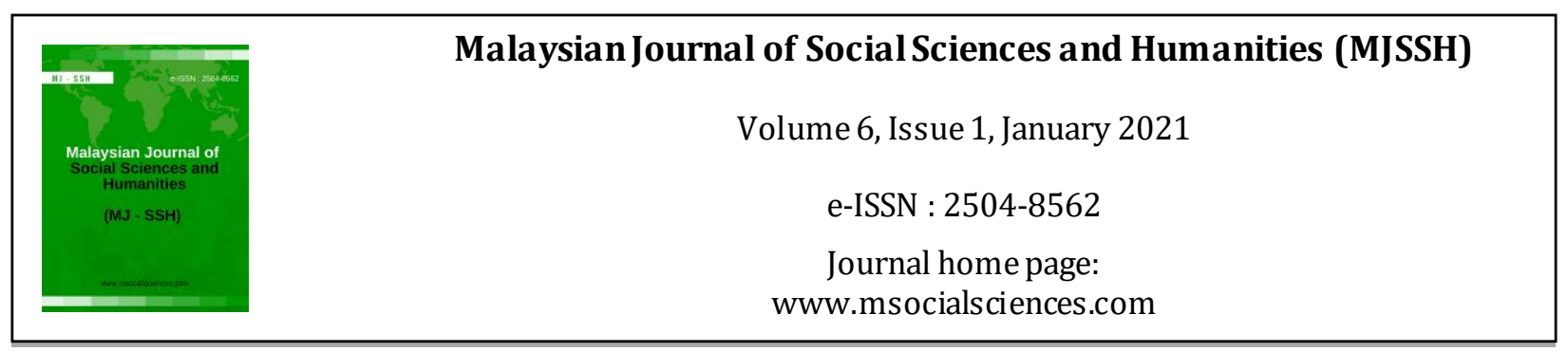

\title{
Spatial Pattern and Hotspots of Urban Rail Public Transport to Public Access Using Geospatial Techniques in Selangor, Malaysia
}

\author{
Mohd Sahrul Syukri Yahya ${ }^{1}$, Edie Ezwan Mohd Safian', Burhaida Burhan' \\ ${ }^{1}$ Department of Real Estate Management, Faculty of Technology Management and Business, Universiti Tun Hussein \\ Onn Malaysia (UTHM)
}

Correspondence: Edie Ezwan Mohd Safian (edie@uthm.edu.my)

\begin{abstract}
Currently, the trends in urban public transport have been changing over the years in developing countries for mobilization and accessibility development. Urban public transportation systems are the most popular in Selangor State, including big cities such as the Klang Valley Region. Objective measures of spatial pattern and hotspots have been used to understand how urban public transport development relate to open access. This method relies on specific spatial information and available web-based tool that shows the pattern primarily based on given vicinity and statistics connectivity. To date, several studies have finished tested in developed countries. In this study, we use Geographic Information Systems to analyse and consider hotspots identification precisely and efficaciously. Therefore, in this paper, we focus on two types of point sample evaluations - Gi* hot spot and point density analysis evaluation as statistical operations. Public rail transport was evaluated as a validation to describe the percentage of distribution of open access. The final result, GIS mapping capabilities to show that GIS's technology offers to the variation of urban public transport relate to public services, is to create maps and spatial interpretations.
\end{abstract}

Keywords: spatial information, Geographic Information System (GIS), public transport, urban, access

\section{Introduction}

Currently, roads and rail are the most important for urban public transportation modes. Urban public transport such as trains, buses, and taxis is vital in reducing traffic congestion in Selangor. Excellent public transportation can be obtained from exploring public facilities. However, the increased number of uses private transport modes and high density of activities make it possible for public transport problems. Prasarana Malaysia Berhad (Prasarana) operates public transport services in Kuala Lumpur and Selangor in Malaysia for the Rapid KL urban rail and bus service (Ho et al., 2017). At the same time, the municipal rail services are managed and operated via Rapid Rail Sdn. Bhd and Rapid KL stage bus service are operated with the aid of Rapid Bus Sdn Bhd. The improvement of public transport and infrastructure transformation to deliver public services for people is one factor within the National Key Results Area (NKRA) (Khalil, 2017). The Development of Regional Master Plans and Strategic of Land Public Transport has been mentioned GIS tools as a support system to decide for the plan. Taxi Transformation Plan (TTP), the Bus Transformation Plan (BTP), and the Urban Rail Development Plan (URDP) are the strategic planning for urban public transport (Polom et al., 2018). Good accessibility, urban public transportation are equipped and supported with universal access to control and monitor 
public transport movement via GPS and Apps. Urban public transport plan provides sustainable development for cities (Uyan et al., 2017).

One of the tools to identify spatial pattern and hotspots are GIS. Researchers for assessment have conducted GIS. Therefore, analysis of spatial patterns and hotspot information using geospatial techniques can determine the distribution of location and point of interest and analyses the conditions, factors, and forecasts of their territorial development after their allocation (Kulyk \& Sossa, 2018). Hot spot cluster analysis is a useful technique for determining where clusters of cases exist (Olfatifar et al., 2017). Getis Ord Gi is a tool to classify hot and cold areas for spatial autocorrelation (Olfatifar et al., 2017; Zheng et al., 2018). Spatial autocorrelation statistics are used in Clusters, randomness, or spatial pattern dispersal (Brianna et al., 2020). Wubuli et al, mentioned that spatial autocorrelation divided into two conditions, which are local and global spatial autocorrelation (Wubuli et al., 2015; Wang et al., 2017). The global spatial autocorrelation calculates the total degree of spatial autocorrelation for a dataset. The local autocorrelation uses the location and types of clusters (Wang et al., 2017).

The previous research was applied in diseases, crime, traffic incidents, forest fire, urbanization growth by development and population and as a tool for prediction. Chainey mentioned hotspot mapping by Getis Ord Gi and Kernel Density to identify crime and use a prediction accuracy index (PAI) to predict crime hotspots (S. Chainey, 2010). Another crime case conducted in Zimbabwe using Getis Ord Gi and Moran I to determine crime clustering and crime hotspots area. This case will help law regulation to reduce crime issues (Mafumbabete et al., 2019). This research used Getis Ord Gi in Tuberculosis Disease in China to detect the spatial clustering area and identified the factor predictors (Wubuli et al., 2015). Seman \& Masron also studied health in 'Hand Foot and Mouth Disease' (HFMD) using Thiessen Polygon and Getis Ord Gi to identify the hotspot in Kuching, Sarawak (Seman \& Masron, 2019). In Brunei, Said studied Getis Ord Gi statistics and Inverse Distance Weighted method for finding hotspots of forest fires and visualization distribution maps in the study area (Said et al., 2017). Additionally, suitable locations for new stations of fire were decided based on various variables. This issue is similar cases to assess new selective railway using GIS by the analytical hierarchical process (AHP) (Amjed et al., 2018).

In conclusion, GIS mapping is a valuable method for studying spatial patterns like random, dispersion, or cluster by focusing on their relationship with the surrounding public facilities. In this study, the Getis Ord Gi method and point density used to define open access hotspots and rail station attributes are evaluated. The map distribution of spatial patterns with GIS was developed (Azeez et al., 2016).

\section{Methodology}

\section{Study area}

Selangor's urban area is the area selected for this study, $7949 \mathrm{~km}^{2}$, and 543,290 ha are developed areas (DOA, 2018). This area located between $3.1856^{\circ} \mathrm{N}$ latitude and $101.6149^{\circ} \mathrm{E}$ longitude. Selangor is the most significant state in Peninsular Malaysia and represents almost $30 \%$ of the total population and estimated at 9.53 million in 2018 (DOSM, 2018). Selangor boundary consists of 11 areas: the Federal Territory of Kuala Lumpur (FTKL), Gombak, Hulu Selangor, Hulu Langat, Klang, Sabak Bernam, Kuala Langat, Kuala Selangor, Sepang, Petaling, and Putrajaya. The study area is shown in Figure 1. In Selangor, the variety of public access and transportation has been identified based on rail station location is shown in Figure 2. 
Figure 1: Geographical map of Selangor State

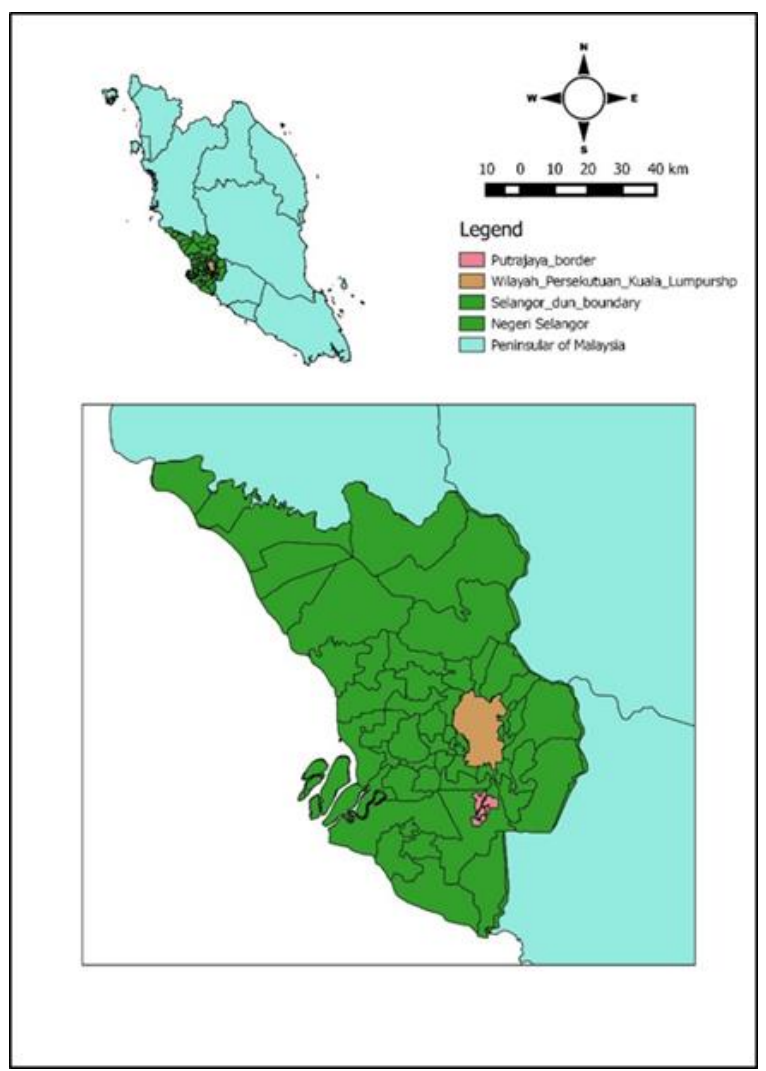

Figure 2: Point location of transport, POI and Station in Selangor

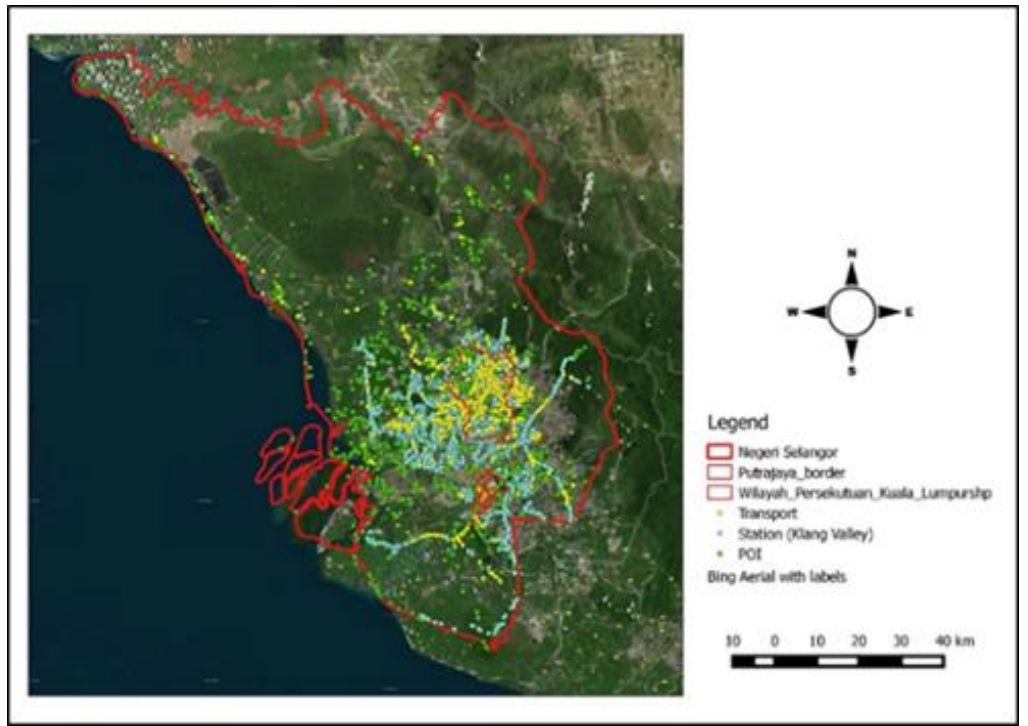

\section{Data and Material}

The dataset for this study has been retrieved from primary and secondary data sources. Google Earth obtained primary source data, DOSM, DOA, and OpenStreet Map. This process has been loaded into GIS software ArcMap version 10.5, enabling us to assign the vector layers and base map to process them together. From the rich available data, the point of interest (POI) has selected for quality assessment. These parameters can be modelled in the GIS environment. Then, spatial analysis can be 
conducted to identify the distribution of urban public transport. The secondary data sources include data capture for map digitizing.

\section{StatisticalMethod}

\section{Point Density Analysis}

Point Density in geoprocessing technique by ArcMap 10.5 for point characters tool to calculate point character density around each raster output cell. A district is determined around every raster cell center; thus, the district's number is totalised and divided by the district (Silverman, 1986; Khosrow-Pour, 2019). Point density analysis may be found in disease cases, criminal cases, traffic incidents, or firms clustering. During this study, one address might represent some extent of open access, or in deciding the public access level, some open access can be weighted more heavily than others. In this situation, it is increasing the radius that will not change the calculated density values. There are more points in the broader district. When measuring density, this number will be divided into a more prominent area. The calculation of a bigger interval and mass considered a more significant amount of points and maybe the most effective outside of the raster cell. In this study, point density analyses are shown with different colours such as blue colour for high density, yellow colour for medium density and red colour for low density.

\section{Moran's I statistics- (Spatial Autocorrelation Analysis)}

Spatial autocorrelation analysis was conducted to assess whether urban public transport was clustered, random, or dispersed (Zheng et al., 2018). SA conducted to demonstrate the spatial relations and surrounding features, and a fixed distance band was chosen. To get the measure of the corresponding to the first peak was performed using the incremental spatial autocorrelation (Zheng et al., 2018). ISA tool of ArcMap 10.5 to carry on the global spatial autocorrelation analysis.

\section{Hot spot analysis}

The measurement of point density can inform us where our data includes clusters. However, we do not seem sure whether these clusters have been randomly generated or some underlying spatial mechanisms behind them. Getis Ord Gi statistic was conducted in ArcGIS 10.5 software. Therefore, two statistics were produced to detect clustering patterns. Namely, the meaning $\mathrm{p}$ and $\mathrm{z}$ of $90 \%, 95 \%$, or $99 \%$ is sure to report these clusters' statistically significant significance. (2018). The higher the zscore for statistically relevant positive z-scores, the more extreme clustering of elevated (hot spot) values. The smaller the $\mathrm{z}$-score is, the more pronounced the clustering with low costs (cold place) is for statistically significant negative z-scores. However, a $\mathrm{z}$ value nearer to zero suggests a lack of spatial clustering (Li \& Yang, 2018). The formula of Getis Ord Gi was calculated as follows (1)

$$
G_{i}^{*}=\frac{\sum_{j-1}^{n} w_{i, j} x_{j}-\bar{X} \sum_{j-1}^{n} w_{i, j}}{s \sqrt{\frac{\left.\left[n \sum_{j=1}^{n} w_{i, j}^{2}-\left(\sum_{j-1}^{n} w_{i, j}\right)^{2}\right)\right]}{n-1}}}
$$

In this analysis, the term $x \mathrm{j}$ refers to the characteristic value of the word $\mathrm{j}$, which term wij refers to the weight of the space between the term $\mathrm{i}$ and $\mathrm{j}$. Term $\mathrm{n}$ refers to the number of locations (Sibanda et al., 2015). The output analysis is $\mathrm{Z}$ ratings, and $\mathrm{p}$-values are used to determine whether the point distributions on a map are hotspot or cold spot regions. In this paper, the spatial clustering pattern was explored using the following steps:

Step 1: The coordinates of location cases were geocoded by GIS and global clustering techniques using Point Density and Incremental spatial autocorrelation to assess and test current facts distribution. 
Step 2: In Getis-Ord Gi * statistics, local spatial clusters were analyzed, and the hot spots and the cold spots separated.

Step 3: The final map was overlaid between rail station points. Please refer to the attachment in Figure 3 for detailed study methods.

Figure 3: Stages in Developing the Point Density and Hot Spot Analysis

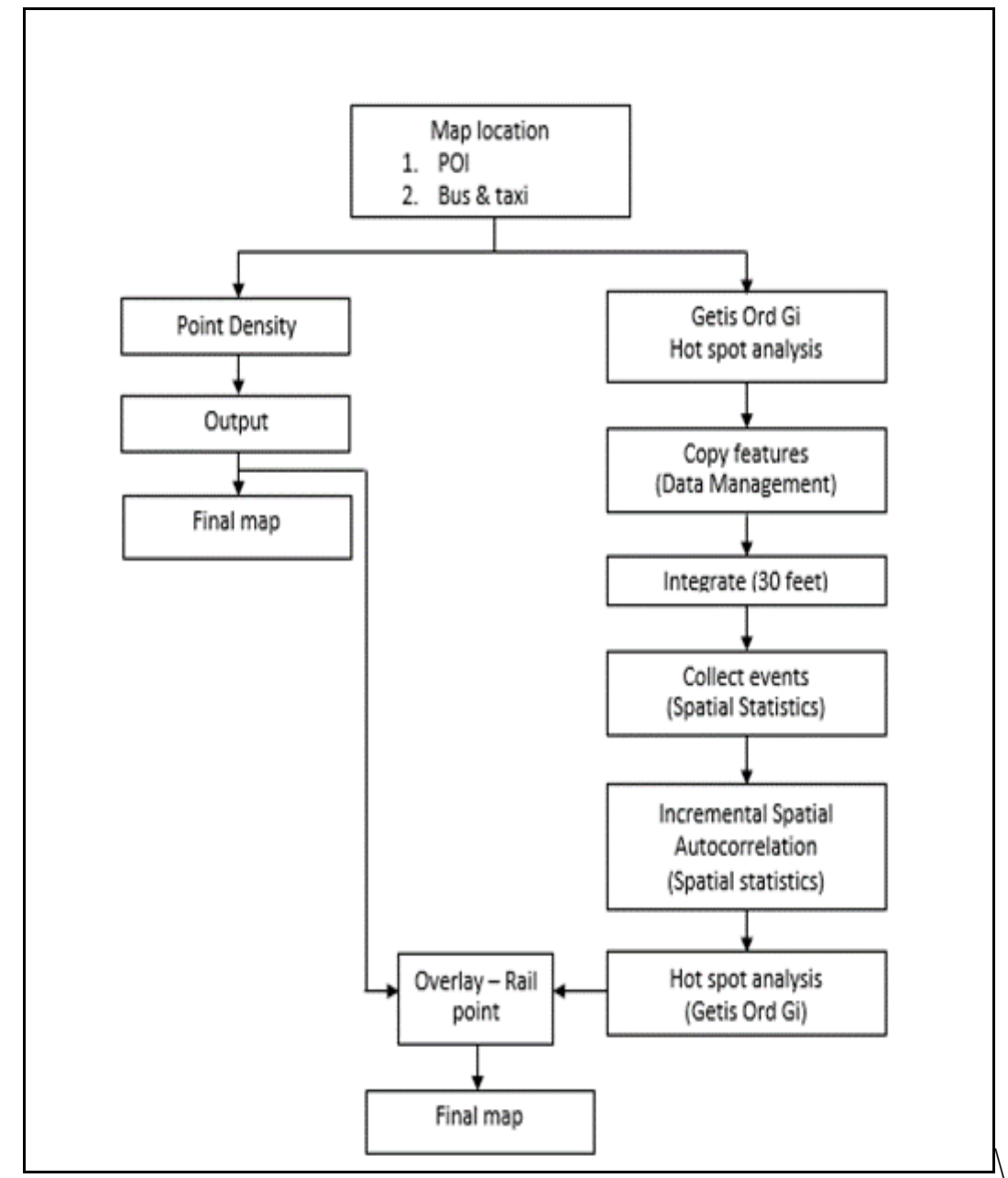

All open access reporting point distribution will be translated to GIS format using a coordinate scheme on the ground. Point pattern analysis will be carried out to determine the cluster, scattered, or randomly distributed distribution of point public access in Selangor areas. Ultimately, Getis Ord Gi can use the nearest average neighbor analysis (ANN). (Kuo et al., 2011).

\section{Result}

\section{Point Density}

Figure 4 describes the distribution of POI by point density analysis in Selangor. Most of these show the high concentration and clustered at the center of city Kuala Lumpur, Shah Alam, Petaling Jaya, and surrounding areas. However, Putrajaya has a medium level density of POI as public access. Figure 5 shows the distribution of transportation density and appeared to be the highest-cluster concentration in Kuala Lumpur City, Petaling Jaya, and Shah Alam. Bus, taxi station and rail station are the types of transportation in these areas. These places also have many variations of the transport systems for all users. Many transport systems could be attracted to all passengers to use public transport in those areas. 
Figure 6 shows that point density analysis showed that more stations (bus and taxi) concentrated and clustered in starting from the Kuala Lumpur area to Port Klang. In this situation, the highest concentration was influenced by population and developed areas. The first railway station and road highway were contributed to the high density.

Figure 4: Distribution of POI by point density in Selangor

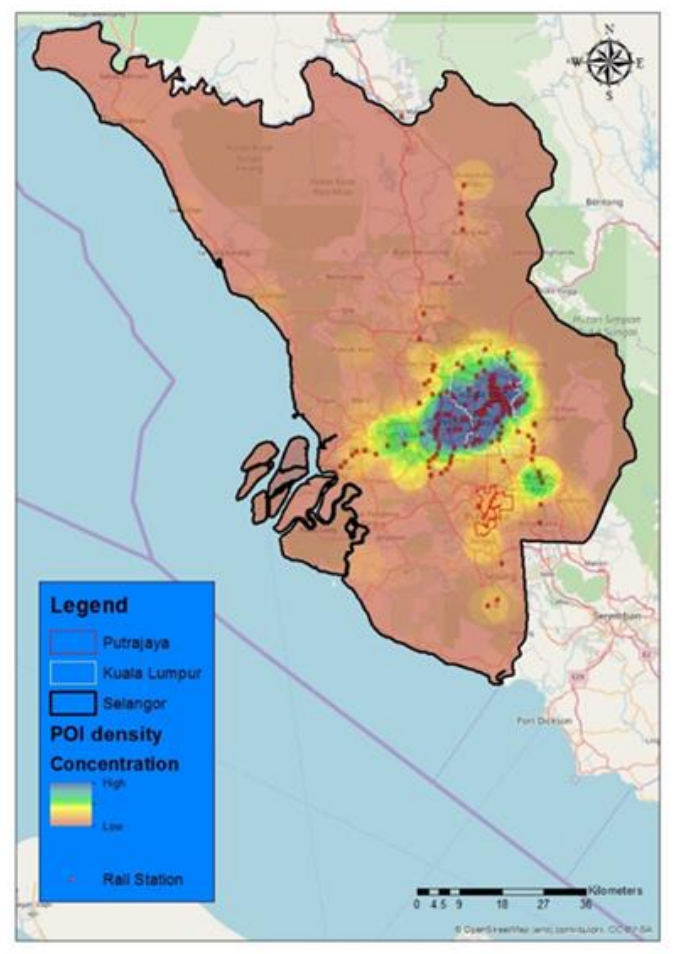

Figure 5: Distribution of transportation by point density in Selangor

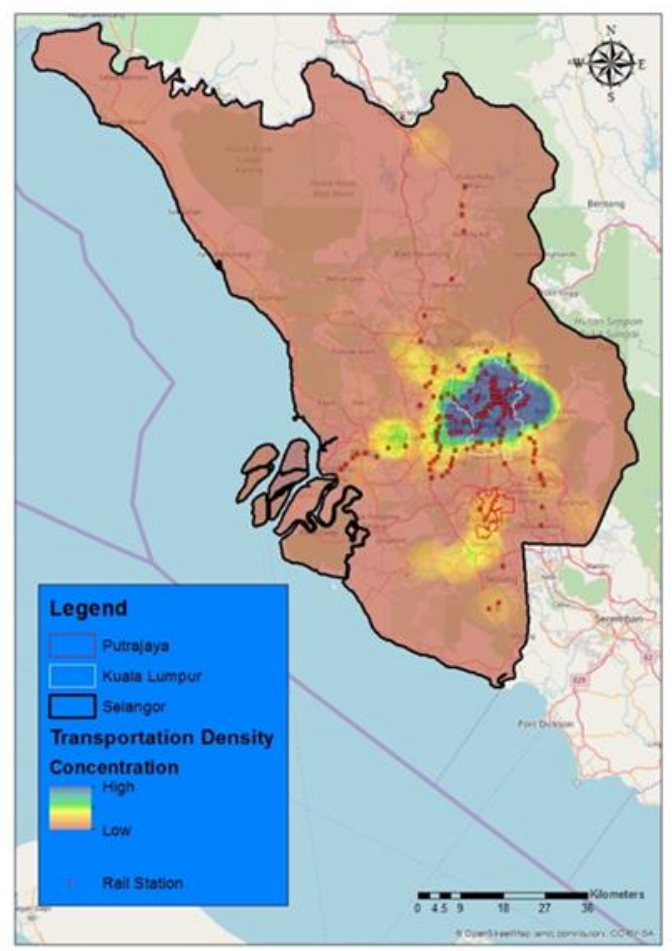


Figure 6: Distribution of Station (bus \& taxi) by point density in Selangor

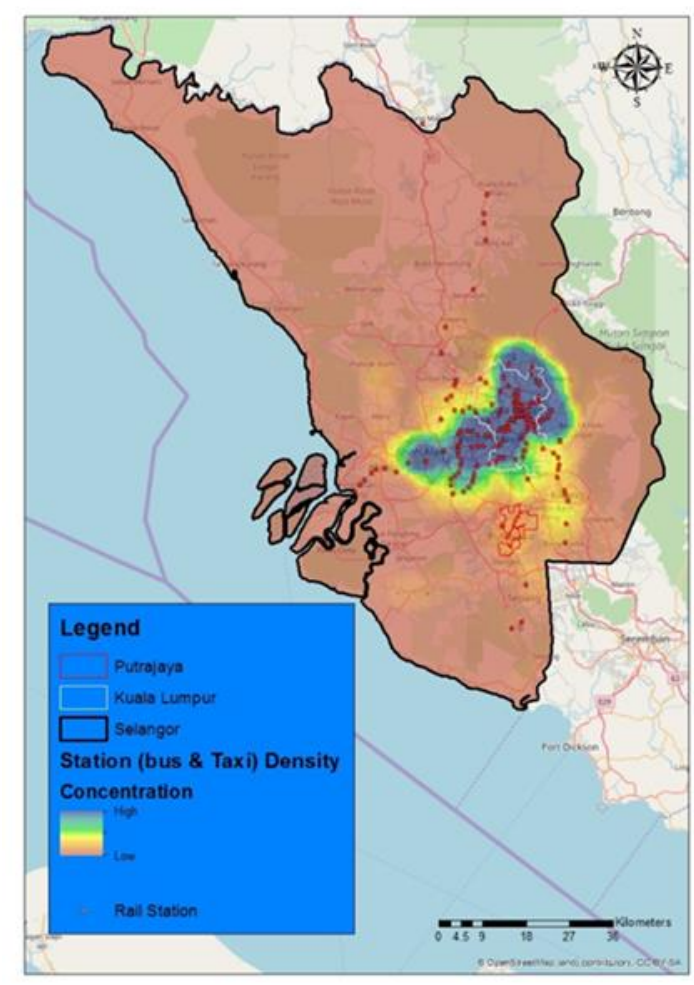

\section{IncrementalSpatialAutocorrelation (ISA)}

ArcMap 10.5 was used to find a distance band with the incremental spatial autocorrelation (ISA) tool. The overall spatial autocorrelation is expressed, and where the resulting z-scores peaked is noted. We used the distance associated with the peak value. ISA uses Spatial Autocorrelation methods to calculate spatial clustering strength or spatial differentiation for each distance (Jiang et al., 2017). The rapid bus results showed that the maximum $\mathrm{z}$-score maximum value with the maximum peak was 62.884041 for the range of $2772.64 \mathrm{~m}$, as shown in figure 7. This value was selected as the parameter for the distance band in hot spot analysis. However, none results showed that the POI for z-score maximum and maximum peak (figure 8). The local spatial study by Getis - Ord Gi* statistic used in showed outstanding spatial aggregation of urban public transport relate public access in classed clusters forming hot spot and cold spot (Shah et al., 2014).

Figure 7: The result of Spatial Autocorrelation by Distance (Public Transport -Bus \& Taxi)

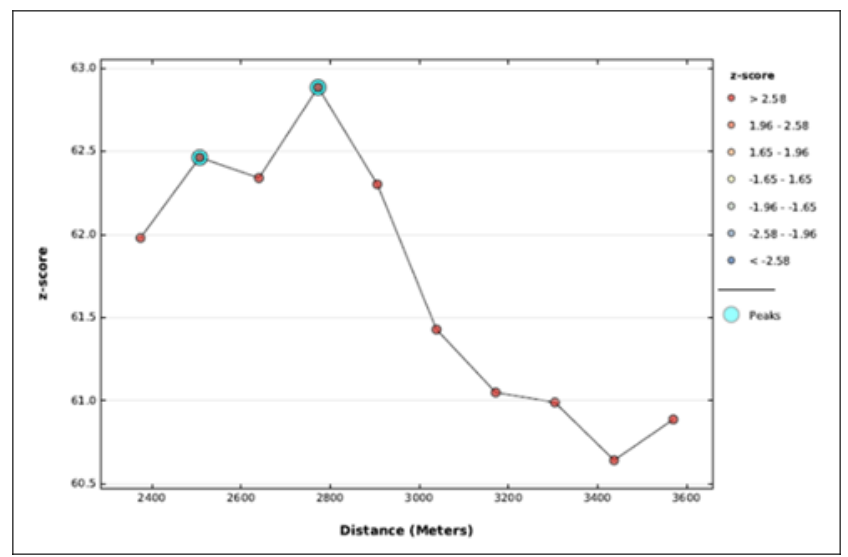


DOI: https://doi.org/10.47405/mjssh.v6i1.634

Figure 8: The result of Spatial Autocorrelation by Distance (POI)

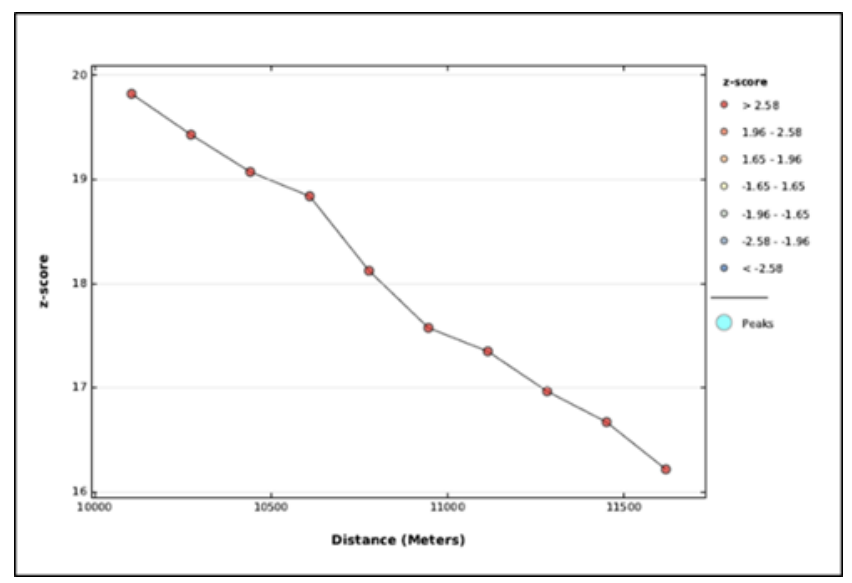

\section{Hotspot Analysis}

The public access in the Selangor area is spatially clustered, according to ISA and point density results. Here, the hot spots of open access between train stations are significantly clustered using Getis Ord Gi analysis. The type of clusters is forming hotspots and coldspots. The red dots are hot spots and higher trust levels for confidence values. The blue dots are cold areas with lower values of trust. Random distribution is shown in yellow. The result indicates that Shah Alam, Gombak, Sepang, and some Kuala Langat area expressed a hot spot map. However, the cold spot area is located at Klang, Kuala Langat, Hulu Langat, North Sepang, and North Gombak. There is no significant spot area for the rest of the District (shown in figure 9). Hotspot areas focus on the center city like Kuala Lumpur because it has good public access and most developing areas. Besides, the highest population is the factor in becoming a hotspot area.

Figure 9: Hotspot analysis for public access and train station in Selangor

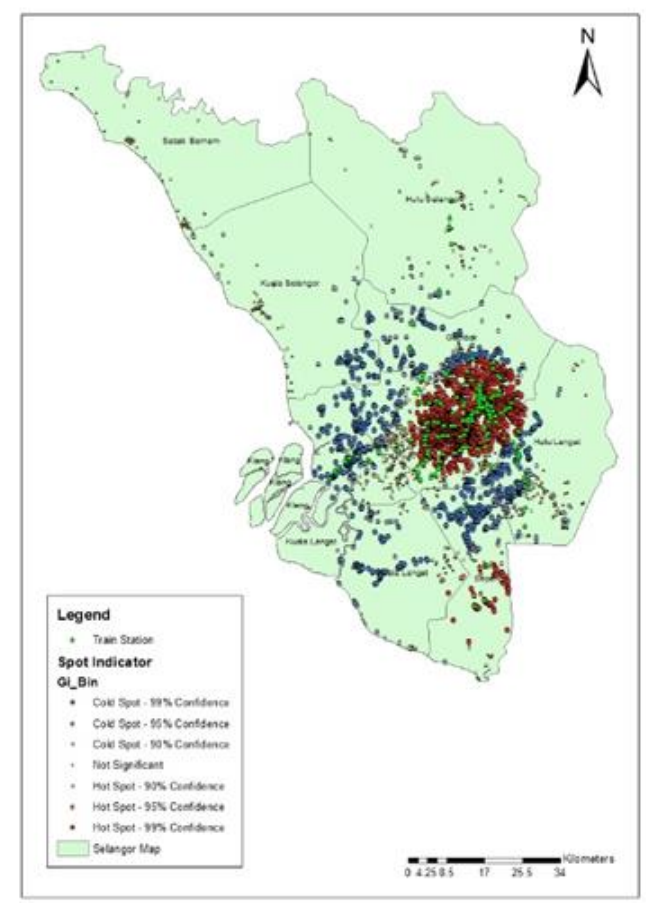

The less concentration spot occurs in a rural area and poor development area. The spot access also focused on the railway station. The relationship between public access and urban rail transport is identified, as shown in table 1. LRT station is the most popular hotspot area compared with other trains. This scenario is because LRT has many lines and trips to any destination. So, the visualization 
point of interest as public access in the study area can predict users' mobility trends. The hot spots will identify possible locations for new transport hubs and the journey to the destination (Moyo \& Musakwa, 2019).

Table 1: The number of spot by train and public access

\begin{tabular}{cccc}
\hline Train & Hotspot & Coldspot & Not significant \\
\hline KTM & 23 & 12 & 11 \\
LRT & 82 & 0 & 6 \\
MRT & 28 & 9 & 3 \\
Skypark & 3 & 0 & 0 \\
ERL & 6 & 0 & 0 \\
\hline
\end{tabular}

\section{Conclusion}

In recent years, Malaysia's public transport has aggressively improved. These improvements have given more opportunities in the development transportation landscape. Urban public transport is a dynamic tool used by transportation planners to solve various transportation-related problems related to traffic congestion in urban areas. In this case study, the development of GIS analysis techniques to manage and share information effectively. Malaysian public transportation is dynamic and diverse and potentially plays an essential role in the event of sustainable urban transportation in the country. This study will perform analysis and brought capabilities of public transport services for all people living.

\section{Acknowledgements}

Research Fund E15501 and GPPS supported this research from Research Management Centre, Universiti Tun Hussein Onn Malaysia (UTHM).

\section{References}

Al-Hameedawi, A., Salih, M., Mohammed, H., \& Hassan, M. 2018. Selecting optimum railway track using GIS techniques. In MATEC Web of Conferences (Vol. 162). EDP Sciences. https://doi.org/10.1051/matecconf/201816203018

Abdul Azeez, P., Mohammed Koya, K., Mathew, K. L., Temkar, G. S., \& Khileri, R. A. 2016. GIS based mapping of spatio-temporal distribution pattern of ribbonfish Trichiurus lepturus (linnaeus, 1758) along Saurashtra coast, India. Indian Journal of Fisheries, 63(4), 10-14. https://doi.org/10.21077/ijf.2016.63.4.52912-02

Chew, B., Satpathy, A., \& Wong, E. 2020. Geospatial analyses to determine academic success factors in California's K-12 education. Annals of GIS, 26(2), 81-100. https://doi.org/10.1080/19475683.2020.1739141

Department of Agriculture (DOA). 2018. Landuse data, Selangor. Ministry of Agriculture Malaysia.

Department of Statistics (DOSM). 2018. Population census, Selangor. Department of Statistics Malaysia.

Ho, P. W., Ghadiri, S. M., \& Rajagopal, P. 2017. Future Parking Demand at Rail Stations in Klang Valley. In MATEC Web of Conferences (Vol. 103). EDP Sciences. https://doi.org/10.1051/matecconf/201710309001

Jiang, Y., Fan, F., Zanoni, I. H., \& Li, Y. 2013. Global diffusion pattern and hot spot analysis of vaccine-preventable diseases. In ISPRS Annals of the Photogrammetry, Remote Sensing and Spatial Information Sciences (Vol. 4, pp. 167-173). Copernicus GmbH. https://doi.org/10.5194/isprs-annals-IV-4-W2-167-2017

Khalil, N. 2017. Polytechnic: Carving a Niche in the Rail Industy, Ministry of Transport Malaysia. 
Khosrow-Pour, D.B.A., M. 2019. Advanced Methodologies and Technologies in Engineering and Environmental Science. IGI Global. http://doi:10.4018/978-1-5225-7359-3.

Kulyk, V., \& Sossa, R. 2018. Determining the tourist attractive regions by gis analysis using heatmaps. Geodesy and Cartography, 44(1), 22-27. https://doi.org/10.3846/gac.2018.882

Kuo, P., Lord, D., \& Walden, T.D. 2011. Using geographical information systems to effectively organize police patrol routes by grouping hot spots of crash and crime data. Third International Conference on Road Safety and Simulation, September 14-16, 2011, Indianapolis, USA

Li, Y., \& Liang, C. 2018. The Analysis of Spatial Pattern and Hotspots of Aviation Accident and Ranking the Potential Risk Airports Based on GIS Platform. Journal of Advanced Transportation, 2018. https://doi.org/10.1155/2018/4027498

Mafumbabete, C., Chivhenge, E., Museva, T., Zingi, G. K., \& Ndongwe, M. R. 2019. Mapping the spatial variations in crime in rural Zimbabwe using geographic information systems. Cogent Social Sciences, 5(1). https://doi.org/10.1080/23311886.2019.1661606

Moyo, T., \& Musakwa, W. 2019. Exploring the potential of crowd sourced data to map commuter points of interest: A case study of Johannesburg. In International Archives of the Photogrammetry, Remote Sensing and Spatial Information Sciences - ISPRS Archives (Vol. 42, pp. 1587-1592). International Society for Photogrammetry and Remote Sensing. https://doi.org/10.5194/isprs-archives-XLII-2-W13-1587-2019

Olfatifar, M., Karami, M., Moghimbeigi, A., Motlagh, A., Rooshanaee, G., Partovipour, E., \& Abdolahi, M. 2017. Spatial clustering of breast cancer: An epidemiological analysis of Iranian women. International Journal of Cancer Management, 10(1). https://doi.org/10.17795/ijcp$\underline{5402}$

Połom, M., Tarkowski, M., \& Puzdrakiewicz, K. 2018. Urban Transformation in the Context of Rail Transport Development: The Case of a Newly Built Railway Line in Gdańsk (Poland). Journal of Advanced Transportation, 2018, 1-15. https://doi.org/10.1155/2018/1218041

S. Chainey. 2010. Advanced hotspot analysis: Spatial significance mapping using Gi*. UCL Jill Dando Institute of Crime Science, University College London, London.

Said, S. N. B. M., Zahran, E.-S. M. M., \& Shams, S. 2017. Forest Fire Risk Assessment Using Hotspot Analysis in GIS. The Open Civil Engineering Journal, 11(1), 786-801. https://doi.org/10.2174/1874149501711010786

Seman, B. B., \& Masron, T. 2019. Hotspot analysis of hand foot and mouth disease (HFMD) using GIS in Kuching, Sarawak, Malaysia. Humanities and Social Sciences Reviews, 7(2), 36-44. https://doi.org/10.18510/hssr.2019.725

Shah, S. A., Neoh, H. M., Rahim, S. S. S. A., Azhar, Z I., Hassan, M. R., Safian, N., \& Jamal, R. 2014. Spatial analysis of colorectal cancer cases in Kuala Lumpur. Asian Pacific Journal of Cancer Prevention, 15(3), 1149-1154. https://doi.org/10.7314/APJCP.2014.15.3.1149

Sibanda, M., Dube, T., Bangamwabo, V. M., Mutanga, O., Shoko, C., \& Gumindoga, W. 2016. Understanding the spatial distribution of elephant (Loxodonta africana) poaching incidences in the mid-Zambezi Valley, Zimbabwe using Geographic Information Systems and remote sensing. Geocarto International, 31(9), 1006-1018. https://doi.org/10.1080/10106049.2015.1094529

Silverman, B. W. 1986. Density Estimation for Statistics and Data Analysis. New York: Chapman and Hall.

Uyan, M., Sert, E., Osmanli, N., \& Eruc, R. 2017. Determination of Transportation Networks Base on The Optimal Public Transportation Policy Using Spatial And Network Analysis Methods: A Case Of The Konya, TURKEY. International Journal of Engineering and Geosciences, 2(1), 27-34. https://doi.org/10.26833/ijeg.286034

Wang, W., Chang, Z., Liu, X., Zhu, J., \& Yu, W. 2017. Evaluation of Fire Ignition Probability Model by Using Spatial Autocorrelation Method: A Case Study in Yunnan Province. Atlantis Press. https://doi.org/10.2991/icammce-17.2017.35

Wubuli, A., Xue, F., Jiang, D., Yao, X., Upur, H., \& Wushouer, Q. 2015. Socio-demographic predictors and distribution of pulmonary tuberculosis (TB) in Xinjiang, China: A spatial analysis. PLoS ONE, 10(12). https://doi.org/10.1371/journal.pone.0144010

Zheng, C., Fu, J., Li, Z, Lin, G., Jiang, D., \& Zhou, X. N. 2018. Spatiotemporal variation and hot spot detection of visceral leishmaniasis disease in Kashi prefecture, China. International Journal of Environmental Research and Public Health, 15(12). https://doi.org/10.3390/ijerph15122784 
Malaysian Journal of Social Sciences and Humanities (MJSSH), Volume 6, Issue 1, (page 234 - 244), 2021

DOI: https://doi.org/10.47405/mjssh.v6i1.634

Adofo, S. (2013). Challenges And Coping Strategies Of Student Nursing Mothers In Tertiary Institutions In The Greater Accra Region Of Ghana (M.Phil). University of Ghana. 